Check for updates

Cite this: RSC Adv., 2018, 8, 29179

Received 7th June 2018

Accepted 10th August 2018

DOI: $10.1039 / c 8 r a 04887 h$

rsc.li/rsc-advances

\section{Annealing temperature effects on photoelectrochemical performance of bismuth vanadate thin film photoelectrodes $\dagger$}

\author{
Le Shi, (DD ${ }^{a}$ Sifei Zhuo, ${ }^{a}$ Mutalifu Abulikemu, ${ }^{a}$ Gangaiah Mettela, ${ }^{a}$ \\ Thangavelu Palaniselvam, ${ }^{a}$ Shahid Rasul, ${ }^{a}$ Bo Tang, ${ }^{a}$ Buyi Yan, ${ }^{b}$ Navid B. Saleh (D) \\ and Peng Wang (D) *a
}

The effects of annealing treatment between $400{ }^{\circ} \mathrm{C}$ and $540{ }^{\circ} \mathrm{C}$ on crystallization behavior, grain size, electrochemical (EC) and photoelectrochemical (PEC) oxygen evolution reaction (OER) performances of bismuth vanadate $\left(\mathrm{BiVO}_{4}\right)$ thin films are investigated in this work. The results show that higher temperature leads to larger grain size, improved crystallinity, and better crystal orientation for the $\mathrm{BiVO}_{4}$ thin film electrodes. Under air-mass 1.5 global (AM 1.5) solar light illumination, the $\mathrm{BiVO}_{4}$ thin film prepared at a higher annealing temperature $\left(500-540{ }^{\circ} \mathrm{C}\right)$ shows better PEC OER performance. Also, the OER photocurrent density increased from $0.25 \mathrm{~mA} \mathrm{~cm}^{-2}$ to $1.27 \mathrm{~mA} \mathrm{~cm}^{-2}$ and that of the oxidation of sulfite, a hole scavenger, increased from 1.39 to $2.53 \mathrm{~mA} \mathrm{~cm}{ }^{-2}$ for the samples prepared from $400{ }^{\circ} \mathrm{C}$ to $540{ }^{\circ} \mathrm{C}$. Open-circuit photovoltage decay (OCPVD) measurement indicates that $\mathrm{BiVO}_{4}$ samples prepared at the higher annealing temperature have less charge recombination and longer electron lifetime. However, the $\mathrm{BiVO}_{4}$ samples prepared at lower annealing temperature have better EC performance in the absence of light illumination and more electrochemically active surface sites, which are negatively related to electrochemical double-layer capacitance $\left(C_{\mathrm{dl}}\right)$. $C_{\mathrm{dl}}$ was $0.0074 \mathrm{mF} \mathrm{cm}^{-2}$ at $400{ }^{\circ} \mathrm{C}$ and it decreased to $0.0006 \mathrm{mF} \mathrm{cm} \mathrm{cm}^{-2}$ at $540{ }^{\circ} \mathrm{C}$. The OER and sulfide oxidation are carefully compared and these show that the efficiency of charge transport in the bulk $\left(\eta_{\text {bulk }}\right)$ and on the surface $\left(\eta_{\text {surface }}\right)$ of the $\mathrm{BiVO}_{4}$ thin film electrode are improved with the increase in the annealing temperature. The mechanism behind the light-condition-dependent role of the annealing treatment is also discussed.

\section{Introduction}

Harvesting solar energy is an effective alternative energy pathway and is desired to mitigate environmental impacts from fossil fuel based energy production., ${ }^{1,2}$ Photoelectrochemical (PEC) water splitting with metal oxide semiconductors has attracted enormous attention in solar energy conversion..$^{3-5}$ Recently, bismuth vanadate $\left(\mathrm{BiVO}_{4}\right)$, an n-type bimetallic oxide semiconductor with a narrow band gap $(\sim 2.4 \mathrm{eV})$, suitable band position, and relatively high stability against photo-corrosion, has distinguished itself as a promising photoanode-material. ${ }^{6,7}$ However, pristine $\mathrm{BiVO}_{4}$ has poor electron-hole separation $^{8}$ and exhibits slow water oxidation kinetics, ${ }^{9}$ which are

${ }^{a}$ Water Desalination and Reuse Center, Division of Biological and Environmental Sciences and Engineering, King Abdullah University of Science and Technology, Thuwal 23955-6900, Saudi Arabia. E-mail: peng.wang@kaust.edu.sa

${ }^{b}$ Division of Physical Science and Engineering, King Abdullah University of Science and Technology, Thuwal 23955-6900, Saudi Arabia

${ }^{c}$ Department of Civil, Architectural and Environmental Engineering, University of Texas at Austin, Austin, TX 78712, USA

$\dagger$ Electronic supplementary information (ESI) available. See DOI: 10.1039/c8ra04887h major obstacles to utilization of the photoreactive capacity of this material.

Recent research has invested into multiple strategies in improving the PEC performance of $\mathrm{BiVO}_{4}$, including heterojunction formation, (e.g., $\mathrm{Co}_{3} \mathrm{O}_{4} / \mathrm{BiVO}_{4},{ }^{10} \mathrm{SnO}_{2} / \mathrm{BiVO}_{4},{ }^{11} \mathrm{WO}_{3} /$ $\mathrm{BiVO}_{4},{ }^{12} \mathrm{TiO}_{2} / \mathrm{BiVO}_{4},{ }^{13,14} \mathrm{AgFeS}_{2}-\mathrm{BiVO}_{4}$ (ref. 15)), doping with Mo or $\mathrm{W}^{\mathbf{1 6 - 1 8}}$ addition of electron collectors, ${ }^{19}$ Plasmonic enhancement, ${ }^{20-23}$ and addition of co-catalysts, such as Co$\mathrm{Pi},{ }^{9,24} \alpha-\mathrm{Fe}_{2} \mathrm{O}_{3},{ }^{25} \mathrm{NiCoO}_{2},{ }^{26}$ and $\mathrm{Ir}-\mathrm{COOH} .{ }^{27} \mathrm{~A}$ closer investigation reveals that there exists a large variation in the generated current (Table S1 $\dagger$ ). Literature reports also highlight the lack of consistency in sample preparation process, including the precursor composition, annealing temperature, etc. (Table S1 $\dagger$ ). Different materials need different optimal annealing temperature and different synthesis conditions. In fact, the annealing temperature is recognized as an essential and critical step in crystallization of $\mathrm{BiVO}_{4},{ }^{28-31}$ but how annealing temperature affects the PEC performance, specially that of $\mathrm{BiVO}_{4}$ thin film electrode, is largely unexplored.

In this study, we systematically investigate the effects of annealing temperature $\left(400-540{ }^{\circ} \mathrm{C}\right)$ on crystallization behavior, surface morphology, and grain size of $\mathrm{BiVO}_{4}$ thin film 
photoelectrodes, prepared by spin-coating. The electrochemical (EC) and PEC performances of the $\mathrm{BiVO}_{4}$ thin film photoelectrodes are carefully assessed in relation to the annealing temperature and other parameters affected by the annealing temperature. First, under dark condition, $\mathrm{BiVO}_{4}$ thin film electrodes prepared at lower temperature produce better electrochemical performance, which might be due to the more electrochemically active sites. Second, under AM 1.5 irradiated conditions, $\mathrm{BiVO}_{4}$ thin film electrodes prepared at higher annealing temperature produce higher photocurrent density. The OER photocurrent density was increased from $0.25 \mathrm{~mA}$ $\mathrm{cm}^{-2}$ to $1.27 \mathrm{~mA} \mathrm{~cm}{ }^{-2}$ for the samples prepared from $400{ }^{\circ} \mathrm{C}$ to $540{ }^{\circ} \mathrm{C}$, which might be due to the less charge recombination controlled by higher degree of crystallinity and bigger grain size, and also better crystal orientation for $\mathrm{O}_{2}$ evolution. This work will attract attention on the annealing temperature effect on the EC and PEC performance of $\mathrm{BiVO}_{4}$ based thin film electrode.

\section{Experimental}

\subsection{Reagents and materials}

Bismuth(III) nitrate pentahydrate $\left(\mathrm{Bi}\left(\mathrm{NO}_{3}\right)_{3} \cdot 5 \mathrm{H}_{2} \mathrm{O}\right.$, purity $\geq$ $98 \%)$, vanadyl acetylacetonate $\left(\mathrm{VO}(\mathrm{acac})_{2}\right.$, purity $\left.\geq 98 \%\right)$, acetylacetone (purity $\geq 99 \%$ ), and methylene blue were procured from Sigma Aldrich (St. Louis, MO, USA). The conductive fluorine-doped tin oxide (FTO) coated glass with a sheet resistance of $7 \Omega \mathrm{sq}^{-1}$ was purchased from Xinyan (Xinyan Technology Co., China). All aqueous solutions were prepared with Millipore deionized (DI) water with a resistivity of $18.2 \mathrm{M} \Omega \mathrm{cm}$.

\subsection{Preparation of $\mathrm{BiVO}_{4}$ thin film photoelectrodes}

The $\mathrm{BiVO}_{4}$ thin films were prepared by spin-coating and in a layer-by-layer fashion. First, the precursor solution was prepared by dissolving $0.40 \mathrm{~g}$ of $\mathrm{Bi}\left(\mathrm{NO}_{3}\right)_{3} \cdot 5 \mathrm{H}_{2} \mathrm{O}$ and $0.22 \mathrm{~g}$ of $\mathrm{VO}(\mathrm{acac})_{2}$ in $10 \mathrm{~mL}$ acetylacetone, under sonication for $10 \mathrm{~h}$ with gentle heating at $40{ }^{\circ} \mathrm{C}$; a dark brown and transparent solution of $80 \mathrm{mM}$ of bismuth and $80 \mathrm{mM}$ of vanadium (atomic ratio $\mathrm{Bi} / \mathrm{V}=1$ ) in acetylacetone was finally obtained.

The fluorine-doped tin oxide glass (FTO glass) was precleaned following a multi-step procedure described as follows: sonication for $20 \mathrm{~min}$ in DI water containing $3 \mathrm{wt} \%$ sodium dodecyl sulfate (SDS), sonication for another $20 \mathrm{~min}$ in DI water, followed by sonication for $20 \mathrm{~min}$ in acetone, and finally sonication for $20 \mathrm{~min}$ in ethanol (96\%) prior to storing in ethanol. The pre-cleaned FTO glass was dried under nitrogen, followed by cleaning with a Plasma cleaner (Harrick Plasma, Ithaca NY, USA) for $2 \mathrm{~min}$, immediately prior to using it as a substrate in spin-coating of the $\mathrm{BiVO}_{4}$ thin film.

The precursor solution of $80 \mu \mathrm{L}$ was spin-coated at $1400 \mathrm{rpm}$ for $20 \mathrm{~s}$ on a CHEMAT Technology Spin coater (KW-4A, Northridge, CA) onto a $2.5 \times 2.5 \mathrm{~cm}$ FTO substrate to ensure complete coverage. Upon evaporation of excess solvent on a hotplate at $100{ }^{\circ} \mathrm{C}$ for $2 \mathrm{~min}$ in ambient air, the coated FTO was heated up to $400-540{ }^{\circ} \mathrm{C}$ for $5 \mathrm{~min}$ in air for pre-crystallization. Four precrystallization temperatures, i.e., 400, 450, 500 and $540{ }^{\circ} \mathrm{C}$, were investigated in this step. The samples were then cooled for
5 min in ambient condition. Multiple samples with 2, 4, 6, and 8 layers of coatings, were prepared for comparison. After deposition of the final layer, the $\mathrm{BiVO}_{4}$ coated FTO electrode was heated on a hotplate at $100{ }^{\circ} \mathrm{C}$ for $2 \mathrm{~min}$, followed by annealing in a muffle furnace at the pre-crystallization temperature for $0.6 \mathrm{~h}$ and at a heating rate of $2{ }^{\circ} \mathrm{C} \mathrm{min}^{-1}$ for further crystallization. The samples were labeled as $\mathrm{BiVO}_{4}-n$, with $n$ being the pre-crystallization and annealing temperature.

\subsection{Material characterization}

The surface characteristics of the $\mathrm{BiVO}_{4}-n$ electrodes were investigated by field-emission scanning electron microscopy (FESEM, Zeiss Merlin, Germany). Surface roughness analysis was carried out by atomic force microscopy (AFM, Agilent 5400 SPM, Agilent Technologies, USA), at scan areas of $2.0 \times 2.0$ $\mu \mathrm{m}$ and $5.0 \times 5.0 \mu \mathrm{m}$ for all samples. Powdered X-ray diffraction (XRD, Bruker D8 Advance diffractometer, USA, using $\mathrm{Cu} \mathrm{K} \alpha$ radiation, $\lambda=1.5418 \AA$ ) was used to characterize the crystallinity of the samples. All samples were analyzed by XRD in the range of $15-70^{\circ}$ at a scan rate of $0.5^{\circ} \mathrm{min}^{-1}$; the crystal sizes of the $\mathrm{BiVO}_{4}-n$ were estimated with the Scherrer formula. ${ }^{32}$ The diffuse reflectance UV-Vis absorption spectra of the samples were recorded with a spectrophotometer (UV 2550, Shimadzu, Japan), with fine $\mathrm{BaSO}_{4}$ powder as a reference. In thermal gravimetric analysis (TGA, NETZSCH, Germany),100 $\mu \mathrm{L}$ precursor was vacuum-dried for $5 \mathrm{~h}$ prior to the measurements. $\mathrm{X}$-ray photoelectron spectroscopy (XPS) results were collected by an Axis Ultra instrument (Kratos Analytical) under ultrahigh vacuum $\left(<10^{-8}\right.$ torr $)$ and by using a monochromatic $\mathrm{Al} \mathrm{K} \alpha \mathrm{X}$-ray source. The adventitious carbon $1 \mathrm{~s}$ peak was calibrated at $285 \mathrm{eV}$ and used as an internal standard to compensate for any charging effects.

\subsection{PEC performance assessment}

The PEC performances of the prepared $\mathrm{BiVO}_{4}-n$ photoelectrodes were evaluated by using a three-electrode configuration (Autolab, PGSTAT302N, Metrohm, The Netherlands), where $\mathrm{BiVO}_{4}$-n electrode was the working electrode, Pt mesh was the counter electrode, and $\mathrm{Ag} / \mathrm{AgCl}$ in $3 \mathrm{M} \mathrm{KCl}$ was the reference electrode. All the three electrodes were immersed in a $60 \mathrm{~mL}$ quartz container containing a supporting electrolyte. The supporting electrolyte used in all the PEC systems was $0.1 \mathrm{M}$ phosphate (KPi) buffer solution ( $\mathrm{pH} 7$ ), unless otherwise specified. Prior to PEC measurement, the electrolyte was purged with $\mathrm{N}_{2}$ for $30 \mathrm{~min}$ to remove dissolved $\mathrm{O}_{2}$ from the electrolyte solution. Light was irradiated from a solar simulator (Oriel® Sol1A Class ABB Solar simulators, Newport, USA). The intensity of the light source was calibrated with a Si diode (Model 818, Newport, USA) to simulate air-mass 1.5 global (AM 1.5) solar light illumination $\left(100 \mathrm{~mW} \mathrm{~cm}^{-2}\right)$. Electrochemical impedance spectroscopy (EIS) was carried out by applying an AC voltage amplitude of $10 \mathrm{mV}$ within the frequency range from $10^{5}$ to $10^{-3}$ in $0.1 \mathrm{M}$ KPi buffer solution under both dark condition and AM 1.5 illumination. The open-circuit photovoltage decay (OCPVD) was monitored by measuring the photovoltage of samples at open circuit condition under irradiated condition followed by dark condition (to 
observe decay curves). The incident-photon to current efficiency (IPCE) spectra was acquired under irradiated condition. The light from a $300 \mathrm{~W}$ Xe lamp (Model 73404, Newport, USA) was focused through the monochromator (Model: 74125, Newport, USA) onto the working electrode, and the monochromator was incremented in the spectral range (350-600 nm) with a sampling interval of $10 \mathrm{~nm}$ and a current sampling time of $50 \mathrm{~s}$. The light intensity and the generated photocurrent were measured with Newport power meter (Model 1918-R, Newport, USA) and Autolab electrochemical workstation (Autolab, PGSTAT302N, Metrohm, The Netherlands), respectively.

\section{Results and discussions}

\subsection{Preparation of the photoelectrodes}

The $\mathrm{BiVO}_{4}$ thin film photoelectrodes are prepared by the layerby-layer spin-coating method. The detailed sample synthesis is described in the Experimental part. It is noteworthy that a gentle heating is necessary for preparing the precursor solution to make sure its coloration changes from green to dark brown before applying it to spin-coating (Fig. S1†). ${ }^{33,34}$ The spincoating cycles of $2,4,6$, and 8 are tested and compared in this study. The UV-Vis spectra of the $\mathrm{BiVO}_{4}$ samples indicate that the light absorption by the samples increases with the number of layers and begins to plateau at and beyond 6 layers (Fig. S2 $\dagger$ ). Thus, the $\mathrm{BiVO}_{4}$ samples with 6 layers are utilized hereinafter, unless otherwise specified. Using the cross-section SEM image (Fig. S3 $\uparrow$ ), the thickness of the 6-layers $\mathrm{BiVO}_{4}$ thin film is estimated to be $\sim 93 \mathrm{~nm}$, which is near the estimated optimal hole diffusion length in $\mathrm{BiVO}_{4}(\sim 100 \mathrm{~nm}) .{ }^{34}$

There are two heating steps in the sample preparation: brief and multiple heating in ambient air for pre-crystallization upon coating each layer and annealing in a muffle furnace at the end after the completion of coating all layers. To assess the effect of temperature on grain size of $\mathrm{BiVO}_{4}, 400,450,500$ and $540{ }^{\circ} \mathrm{C}$ conditions are investigated in both pre-crystallization and annealing steps. For the purpose of simplification, the temperatures of the pre-crystallization and annealing for the same sample are kept the same in this study. The temperature range is chosen based on the thermal gravimetric analysis (TGA) (Fig. S4 $\dagger$ ). The TGA result shows a clear weight change of the $\mathrm{BiVO}_{4}$ before $400{ }^{\circ} \mathrm{C}$, indicating the conversion of the precursor to $\mathrm{BiVO}_{4}$ has to be accomplished above $400{ }^{\circ} \mathrm{C}$, and this is in agreement with the literature report. ${ }^{35}$ Considering the fact that the FTO glass (7 $\Omega \mathrm{sq}^{-1}$, Xinyan, Inc.) is produced with the annealing temperature of $600{ }^{\circ} \mathrm{C}, 540{ }^{\circ} \mathrm{C}$ is chosen to be the highest annealing temperature in this work. XRD results of BVO-540 samples annealed at different duration time are presented Fig. S5, $\uparrow$ which indicate that $0.6 \mathrm{~h}$ annealing duration is long enough for complete crystallization.

\subsection{Crystallinity and light absorption properties of the photoelectrodes}

The diffraction peaks at $18.9^{\circ}, 28.9^{\circ}, 30.56^{\circ}, 40.05^{\circ}$ and $42.5^{\circ}$ (Fig. 1a) of the XRD spectrum identify that all $\mathrm{BiVO}_{4}$ samples possess a scheelite-monoclinic (s-m) phase (JCPDS 14-0688), which is known for its improved photocatalytic activity in $\mathrm{O}_{2}$ evolution among all the $\mathrm{BiVO}_{4}$ crystalline phases; ${ }^{28,37,38}$ scheelite-tetragonal (s-t) and zircon-tetragonal (z-t) are the other two crystal phases. It should be noted that no bismuth or vanadium oxide phase impurities have been identified. The additional diffraction peaks observed can be assigned to the FTO substrate, as expected from a thin $\mathrm{BiVO}_{4}$ coated glass surface.

The full width at half maximum (FWHM) at the peak (013) (112) is 0.408, 0.312, 0.229, and 0.114 for $\mathrm{BiVO}_{4}-400, \mathrm{BiVO}_{4}-450$, $\mathrm{BiVO}_{4}-500$, and $\mathrm{BiVO}_{4}-540$, respectively, and this decreasing trend with the increase in annealing temperature indicates that the crystallinity of $\mathrm{BiVO}_{4}$ improves with annealing temperature. The crystal sizes are calculated using the Scherrer formula:

$$
D=\frac{K \lambda}{\beta \cos \theta}
$$

where, $D$ is the approximate size of the ordered (crystalline) domains, which may be smaller or equal to the grain size; $K$ is a dimensionless shape factor, with a typical value of 0.94 was used in this work; $\lambda$ is the wavelength of the X-ray radiation $(1.5418 \AA) ; \beta$ is the peak width at the half-maximum intensity,
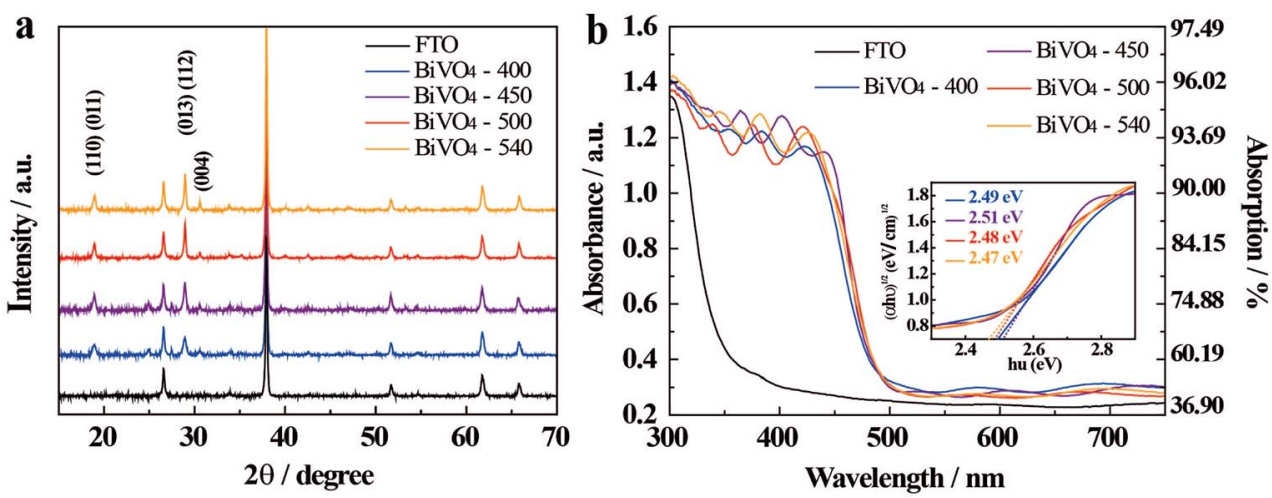

Fig. 1 (a) XRD spectra and (b) UV-Vis absorption spectra of $\mathrm{BiVO}_{4}-n$ samples; FTO-glass control spectrum is also presented. Absorption $Y$ and absorbance $\log _{10}(1 /(1-Y))$ were measured between 300 and $750 \mathrm{~nm}$. Inset in (b) shows transformed Kubelka-Munk functions ${ }^{36}$ for each sample as a function of energy of illumination. 
after subtracting the instrumental line broadening; $\theta$ is the Bragg diffraction angle. The crystal sizes calculated based on the (013) (112) peak are listed in Table $S 2, \dagger$ which confirms increasing crystal size with annealing temperature.

Moreover, the peak intensity ratios of the (004) and (112) facets are 0.213, 0.172, 0.178, and 0.227 for $\mathrm{BiVO}_{4}-400, \mathrm{BiVO}_{4}$ $450, \mathrm{BiVO}_{4}-500$, and $\mathrm{BiVO}_{4}-540$, respectively; while those of the (004) and (110) facets are 0.357, 0.313, 0.400, and 0.550 for $\mathrm{BiVO}_{4}-400, \mathrm{BiVO}_{4}-450, \mathrm{BiVO}_{4}-500$, and $\mathrm{BiVO}_{4}-540$, respectively. It is evident that when the annealing temperature is higher than $450{ }^{\circ} \mathrm{C}$, the fraction of exposed (004) surface in $\mathrm{BiVO}_{4}$ thin film electrode increases significantly. This enhancement in the exposure of (004) crystal facets is known to be beneficial for PEC water oxidation as these facets may provide active sites for $\mathrm{O}_{2}$ evolution. $^{39-41}$ These results demonstrate that the annealing temperature significantly affects the crystallinity and crystal orientation of the $\mathrm{BiVO}_{4}$ thin-film. In addition, the diffraction peat at $25^{\circ}$ is coming from adsorbed carbon contaminants in the sample preparation process, which can be completely removed by increasing the annealing temperature. XPS analysis was carried out to gain addition insights (Fig. S6†) and all the discussion in details are presented in ESI. $\dagger$

The effect of the annealing temperature on the light absorption properties is investigated by UV-Vis absorption and diffuse reflectance spectra ${ }^{7,42,43}$ (Fig. $1 \mathrm{~b}$ and $\mathrm{S} 7 \dagger$ ) and the results show no obvious effect in the temperature range tested. This is likely due to the similar thickness of the samples as these are coated with the same number of layers. Interestingly, both periodic absorption and reflection peaks are observed, which are likely a result of a periodically ordered surface morphology and of uniform size of the grains in the $\mathrm{BiVO}_{4}$ thin films. ${ }^{44}$

\subsection{Surface morphology of the photoelectrodes}

Fig. 2 presents representative SEM images of the $\mathrm{BiVO}_{4}-n$ samples; the crystals appear to be sintered together to form a relatively compact thin film. However, some surface cavities are visible in $\mathrm{BiVO}_{4}-400$, and these cavities begin to disappear with the increase in annealing temperature. The surface grain sizes are observed to be smaller in $\mathrm{BiVO}_{4}-400$ and $\mathrm{BiVO}_{4}-450$, compared to those in $\mathrm{BiVO}_{4}-500$ and $\mathrm{BiVO}_{4}-540$ samples, which further illustrate the effect of annealing temperature on grain size. The grain size distributions are derived from the SEM images in Fig. 2. Average grain size and grain size range increase with annealing temperature (Table S2 $\dagger$ ). These results suggest that the higher temperature favors crystals with larger grain size. The estimated coefficients of variation of the grain size indicate that grain size distribution is not uniform at $540{ }^{\circ} \mathrm{C}$ (Table S2 $\dagger$ ). Furthermore, the average grain sizes estimated from SEM images (Fig. 2) show similar trend when compared to the crystal sizes estimated from XRD analyses (Table S3 $\dagger$ ). These results imply that the $\mathrm{BiVO}_{4}$ grains are largely single crystal in each grain in the thin film photoelectrodes prepared especially at lower temperature.
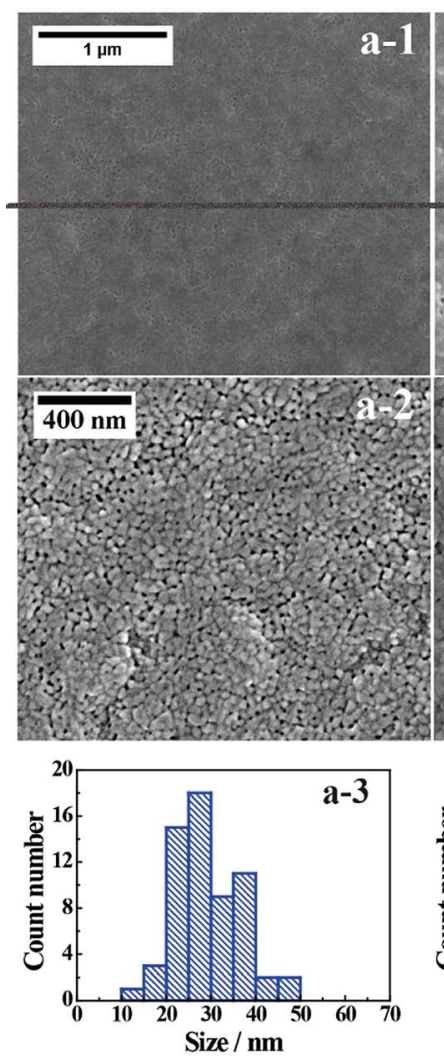
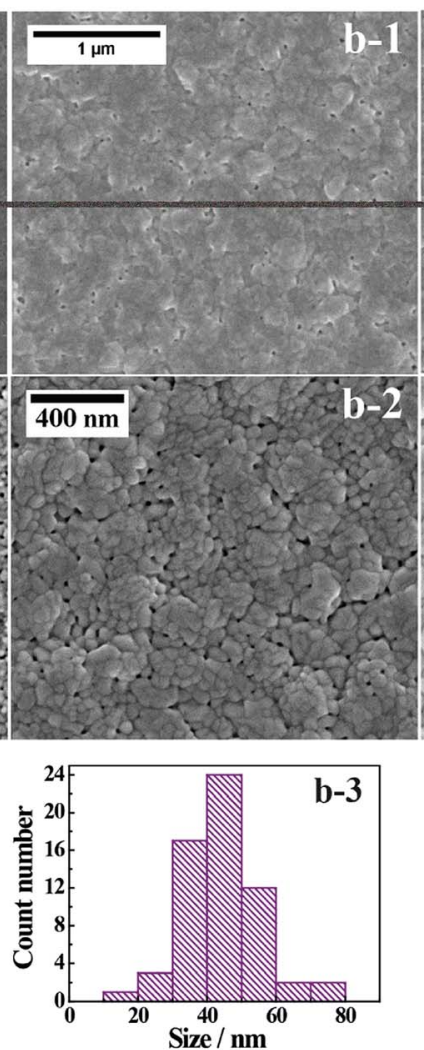
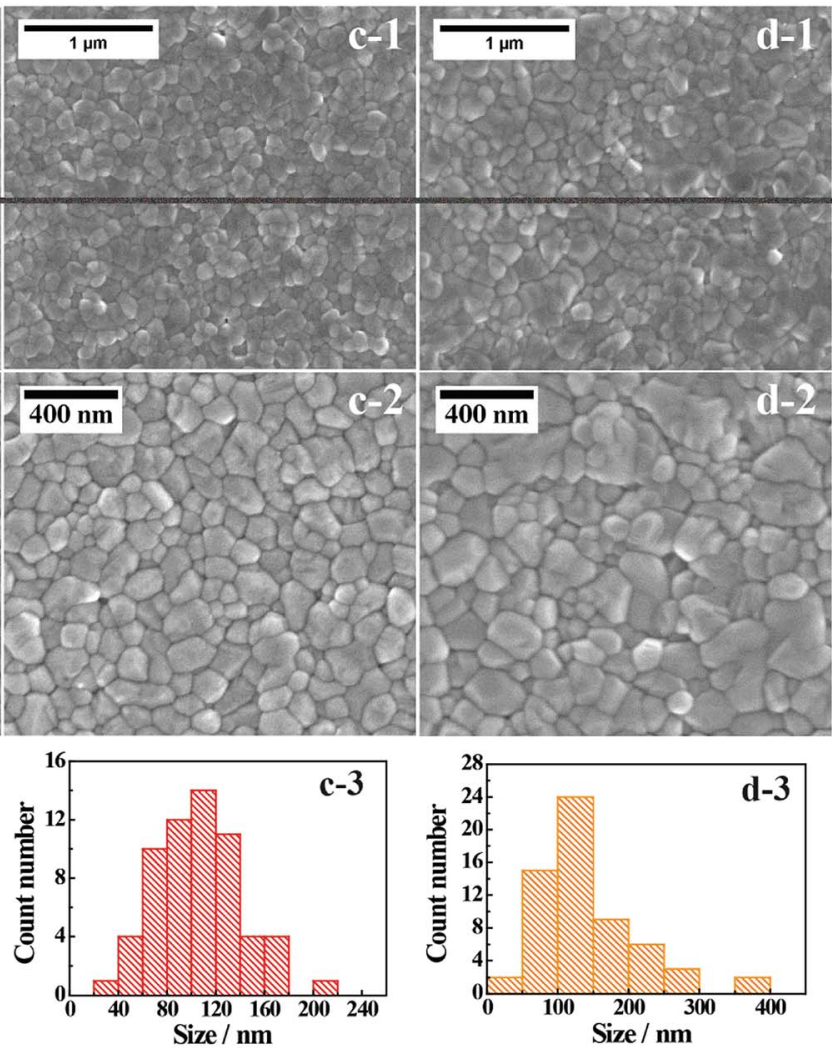

Fig. 2 Top view SEM images of (a1 and a2) $\mathrm{BiVO}_{4}-400$, (b1 and b2) $\mathrm{BiVO}_{4}-450$, (c1 and c2) BiVO $4-500$, and (d1 and d2) BiVO -540 . Grain size $(\mathrm{nm})$ distributions derived from SEM images of each sample (a3-d3). 
AFM analysis is conducted to investigate surface morphology of the thin film $\mathrm{BiVO}_{4}$ photoelectrodes (Fig. S8 and S9†). Rootmean-square roughness (Rms), a reliable parameter for quantifying surface micro-roughness, ${ }^{45}$ is estimated as $12.9 \mathrm{~nm}$, $13.8 \mathrm{~nm}, 13.7 \mathrm{~nm}$, and $13.5 \mathrm{~nm}$ for $\mathrm{BiVO}_{4}-400, \mathrm{BiVO}_{4}-450$, BiVO $_{4}-500$, and BiVO $_{4}-540$, respectively. The annealing temperature shows little effect on surface roughness changes among the $\mathrm{BiVO}_{4}-n$ photoelectrodes.

\subsection{PEC performances of the photoelectrodes}

The PEC performances of $\mathrm{BiVO}_{4}-n$ samples are investigated in a standard three-electrode system and under illumination with a standard AM 1.5G simulated solar light $\left(100 \mathrm{~mW} \mathrm{~cm}^{-2}\right)$. The irradiated was incident on the backside of the $\mathrm{BiVO}_{4}$ photoelectrodes, i.e., on the side with no exposed $\mathrm{BiVO}_{4}$ thin film. The potential is reported against the reversible hydrogen electrode (RHE) with the following equation:

$$
E_{\mathrm{RHE}}=E_{\mathrm{Ag} / \mathrm{AgCl}}+0.059 \mathrm{pH}+E_{\mathrm{Ag} / \mathrm{AgCl}}^{\circ}
$$

where, $E_{\mathrm{RHE}}$ is the potential of working electrode against the electrolyte solution with respect to RHE, $E_{\mathrm{Ag} / \mathrm{AgCl}}$ is the potential of working electrode measured with respect to silver chloride electrode, $\mathrm{pH}$ is that of the electrolyte solution and $E_{\mathrm{Ag} / \mathrm{Agcl}}^{\circ}$ is the potential of the silver chloride electrode with respect to normal hydrogen electrode (NHE), which is $0.1976 \mathrm{~V}$ at $25{ }^{\circ} \mathrm{C}$.

The linear sweep voltammetry (LSV) curves presented in Fig. 3a show that the photocurrents increase with increasing potential, which is expected when enhanced band bending occurs, and when electron-hole recombination (at high potential) is reduced. ${ }^{46}$ The photocurrents at $1.23 \mathrm{~V} v s$. RHE in $0.1 \mathrm{M}$ KPi solution increase with increasing annealing temperature $\left(0.25,0.69,1.18\right.$, and $1.27 \mathrm{~mA} \mathrm{~cm}{ }^{-2}$ for $\mathrm{BiVO}_{4}-400, \mathrm{BiVO}_{4}-450$, $\mathrm{BiVO}_{4}-500$ and $\mathrm{BiVO}_{4}-540$, respectively) (Fig. 3a).

To investigate the surface reaction kinetics of $\mathrm{BiVO}_{4}-n$ samples, the PEC performances of the $\mathrm{BiVO}_{4}$ photoelectrodes are also measured in the presence of a hole-scavenger in the electrolyte (i.e., in this case, $1 \mathrm{M} \mathrm{Na}_{2} \mathrm{SO}_{3}$ in $0.1 \mathrm{M} \mathrm{KPi}$ ) (Fig. 3c and d). Results indicate that PEC performance is enhanced with sulfite oxidation (Fig. 3c) compared to water oxidation (Fig. 3a). The photocurrent densities are $1.39,1.68,2.31$, and $2.53 \mathrm{~mA}$ $\mathrm{cm}^{-2}$ for $\mathrm{BiVO}_{4}-400, \mathrm{BiVO}_{4}-450, \mathrm{BiVO}_{4}-500$ and $\mathrm{BiVO}_{4}-540$, respectively at $1.23 \mathrm{~V} v s$. RHE.

The comparison provides convincing evidence of poor water oxidation kinetics by the $\mathrm{BiVO}_{4}$ thin film photoelectrodes, which is likely caused by the competition between the surface charge transfer and charge recombination. ${ }^{47}$

The poor water oxidation kinetics of $\mathrm{BiVO}_{4}-n$ samples is also evidenced in the large photocurrent transients, when illumination is turned on and off (Fig. S10†). The photoresponse of the samples over time is measured at $1.23 \mathrm{~V}$ vs. RHE in $0.1 \mathrm{M}$ KPi buffer (Fig. S10a $\dagger$ ) and in 0.1 $\mathrm{M} \mathrm{KPi} \mathrm{containing} 1 \mathrm{M} \mathrm{Na}_{2} \mathrm{SO}_{3}$ (Fig. S10b $\dagger$ ) under AM 1.5G illumination with $50 \mathrm{~s}$ light on/off cycles. Normalized photocurrent transient behaviors are also depicted in Fig. S10. $\dagger$ For water oxidation, an anodic photocurrent spike appears for all samples as soon as the light is turned on, and it decreases thereafter; which is supposedly caused by charge recombination and slow interfacial hole transfer kinetics of $\mathrm{BiVO}_{4}$ during water oxidation. ${ }^{47,48}$ In contrast, the presence of the hole scavenger (i.e., $\mathrm{Na}_{2} \mathrm{SO}_{3}$ ) eliminates the sharp photocurrent spike for all samples, which is attributed to depressed charge recombination due to the facilitated hole transfer kinetics. ${ }^{\mathbf{9 4 9 , 5 0}}$ Surprisingly, when in dark, $\mathrm{BiVO}_{4}-400$ and $\mathrm{BiVO}_{4}-450$ show a cathodic shift of the onset potential relative to $\mathrm{BiVO}_{4}-500$ and $\mathrm{BiVO}_{4}-540$ and exhibit consistently better water oxidation and sulfite oxidation performances (Fig. 3b and d); which implies that $\mathrm{BiVO}_{4}-400$ and $\mathrm{BiVO}_{4}-450$ have higher surface catalytic-activities. ${ }^{\mathbf{1 0}}$

Electrochemical impedance spectroscopy (EIS) is also performed for studying $\mathrm{BiVO}_{4}-n$ samples' PEC properties. Fig. S11† presents Nyquist plots for $\mathrm{BiVO}_{4}-n$ samples in dark condition and under AM 1.5 irradiation. It is known that the semicircle in a Nyquist plot at high frequencies is characteristic of charge transfer resistance $\left(R_{\mathrm{ct}}\right)$. By comparison, it is clear to find that $R_{\text {ct }}$ of all $\mathrm{BiVO}_{4}-n$ samples under illumination is lower than the $R_{\text {ct }}$ in dark, which is caused by the increase in electron conductivity of the photoelectrodes under illumination. In dark (Fig. S11a $\dagger$ ), $\mathrm{BiVO}_{4}$ samples prepared at lower temperature show a smaller $R_{\mathrm{ct}}$, and such trend is observed to reverse when irradiated (Fig. S11 $\mathrm{b}_{\dagger}^{\dagger}$ ). The difference in trend in dark $v s$. irradiated conditions can explain in part, the difference in trend in the PEC performance, as presented earlier.

Incident photon to electron conversion efficiency (IPCE) spectra are measured from $350 \mathrm{~nm}$ to $600 \mathrm{~nm}$ and calculated using the following equation: ${ }^{51}$

$$
\operatorname{IPCE}(\%)=\left[1240 I(\lambda) / \lambda J_{\text {light }}(\lambda)\right] \times 100 \%
$$

where, $\lambda$ is the incident light wavelength, $I(\lambda)$ is the measured photocurrent density corresponding to the recorded intensity $J_{\text {light }}(\lambda)$ at the specific wavelength of $\lambda$. The IPCE values of $\mathrm{BiVO}_{4}$ $n$ samples for water oxidation increase with annealing temperature at any tested wavelength, with IPCE at $400 \mathrm{~nm}$ being 5.7, 14.2, 25.8, and $26.9 \%$ for $\mathrm{BiVO}_{4}-400, \mathrm{BiVO}_{4}-450, \mathrm{BiVO}_{4}-500$ and $\mathrm{BiVO}_{4}-540$, respectively (Fig. 4a). The IPCE results are consistent with the previous PEC water oxidation performance, indicating the benefit of high-temperature annealing for $\mathrm{BiVO}_{4}$ thin film photoelectrodes.

\subsection{Electrochemical properties of the photoelectrodes}

In order to further explain the effect of annealing temperature on the $\mathrm{BiVO}_{4}$ photoelectrodes, the efficiency of charge transport in the bulk $\left(\eta_{\text {bulk }}\right)$ and on the surface $\left(\eta_{\text {surface }}\right)$ of $\mathrm{BiVO}_{4}-n$ samples are determined and presented in Fig. $4 \mathrm{~b}$ and c (detailed calculation is given in ESI $\dagger$ ). The $\eta_{\text {bulk }}$ values at $1.23 \mathrm{~V} v s$. RHE are $24 \%, 29 \%, 35 \%$ and $39 \%$ for $\mathrm{BiVO}_{4}^{-400}, \mathrm{BiVO}_{4}-450, \mathrm{BiVO}_{4^{-}}$ 500 and $\mathrm{BiVO}_{4}-540$, respectively, showing an increasing trend with the increase in annealing temperature. Increased bulk separation efficiency with increased annealing temperature is likely due to better crystallinity and increased grain size of $\mathrm{BiVO}_{4}$, which decrease recombination defects in the bulk and inside the grains. $\eta_{\text {surface }}$ is also improved by high-temperature annealing, with the values at $1.23 \mathrm{~V}$ vs. RHE being $19 \%, 41 \%$, $51 \%$, and $50 \%$ for $\mathrm{BiVO}_{4}-400, \mathrm{BiVO}_{4}-450, \mathrm{BiVO}_{4}-500$ and $\mathrm{BiVO}_{4}-$ 

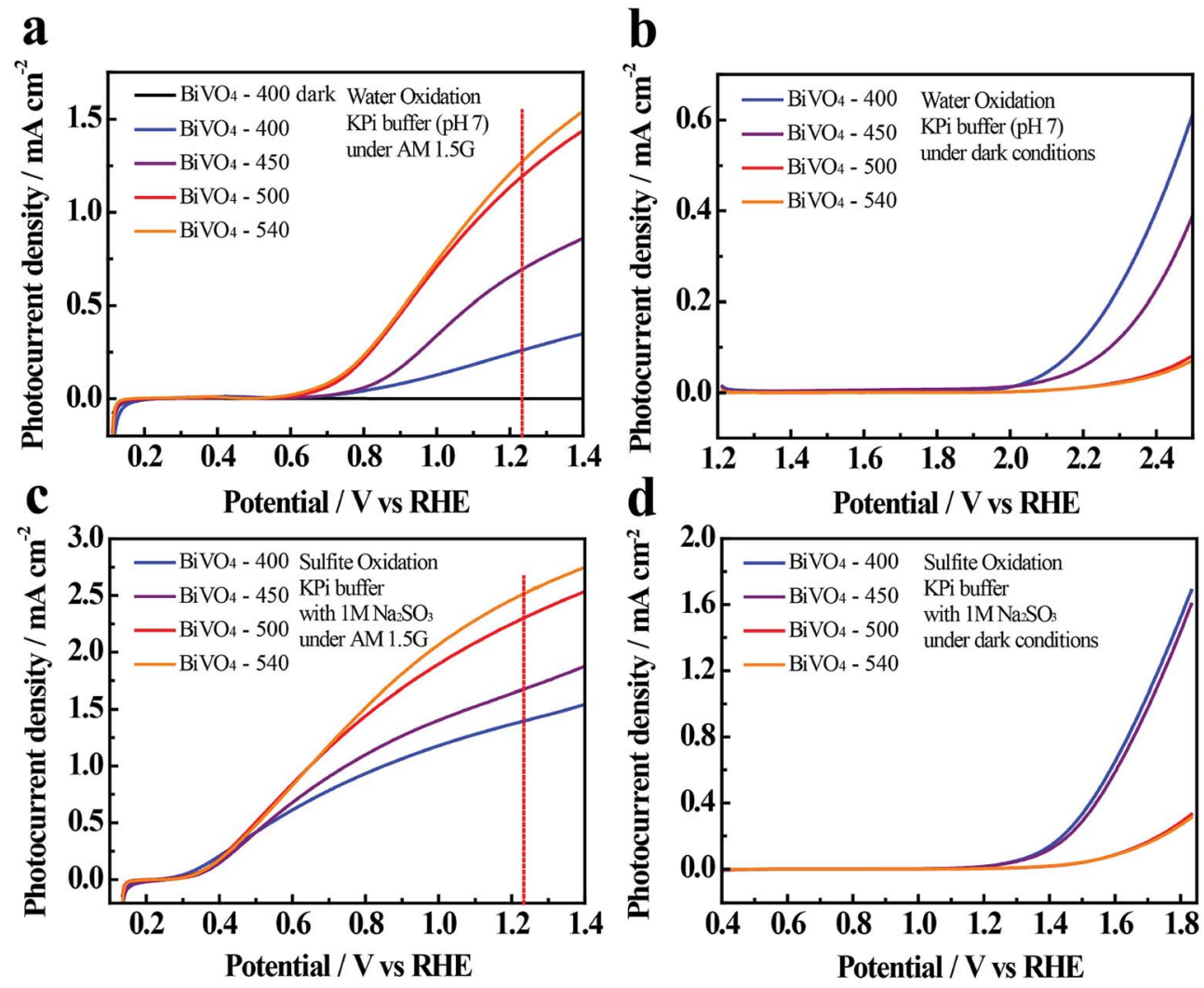

Fig. 3 Linear sweep voltammetry (LSV) curves of $\mathrm{BiVO}_{4}-n$ samples obtained at a scan rate of $5 \mathrm{mV} \mathrm{s}^{-1}$ in dark or under AM 1.5 illumination. Water oxidation in $0.1 \mathrm{M}$ potassium phosphate (KPi) buffer $(\mathrm{pH}-7)$ under illuminated (a) and dark (b) conditions. Sulfite oxidation in $0.1 \mathrm{M} \mathrm{KPi}$, containing $1 \mathrm{M} \mathrm{Na}_{2} \mathrm{SO}_{3}$ under illuminated (c) and dark (d) conditions.

540, respectively. Increased surface separation efficiency is likely due to the previously discussed crystal properties that reduce charge recombination centers on the surface of $\mathrm{BiVO}_{4}$ thin film photoelectrodes. However, the insignificant difference of $\eta_{\text {surface }}$ between $\mathrm{BiVO}_{4}-500$ and $\mathrm{BiVO}_{4}-540$ deserves further attention.

Electrochemical double-layer capacitance $\left(C_{\mathrm{dl}}\right)$ is positively proportional to the electrochemically active sites. Since it is more convenient to measure $C_{\mathrm{dl}}$ than quantitatively characterize electrochemically active sites, $C_{\mathrm{dl}}$ of $\mathrm{BiVO}_{4}-n$ samples are measured to compare the electrochemically active surface areas of these samples. $C_{\mathrm{d} l}$ is measured through cyclic voltammetry (CV) potentiostatic scans in a non-faradaic potential region with different scan rates ranging from 20 to $180 \mathrm{mV} \mathrm{s}^{-1}$ (Fig. S12 and S13 $\dagger$ ). The potential range is $0.23-0.36 \mathrm{~V} v s$. RHE for light condition and $0.47-0.6 \mathrm{~V} v$ s. RHE for dark. In dark, the $C_{\mathrm{dl}}$ is determined to be $0.0074,0.0035,0.0019$, and $0.0006 \mathrm{mF}$ $\mathrm{cm}^{-2}$ for $\mathrm{BiVO}_{4}-400, \mathrm{BiVO}_{4}-450, \mathrm{BiVO}_{4}-500$, and $\mathrm{BiVO}_{4}-540$, respectively (Fig. 5a). Therefore, the $\mathrm{BiVO}_{4}$ samples prepared at lower temperatures possess higher electrochemically active surface areas compared to the $\mathrm{BiVO}_{4}$ samples prepared at higher temperature. The higher electrochemically active surface areas lead to high electrocatalytic activity, which contributes to the cathodic shift of the onset potential under dark condition (Fig. 3d).
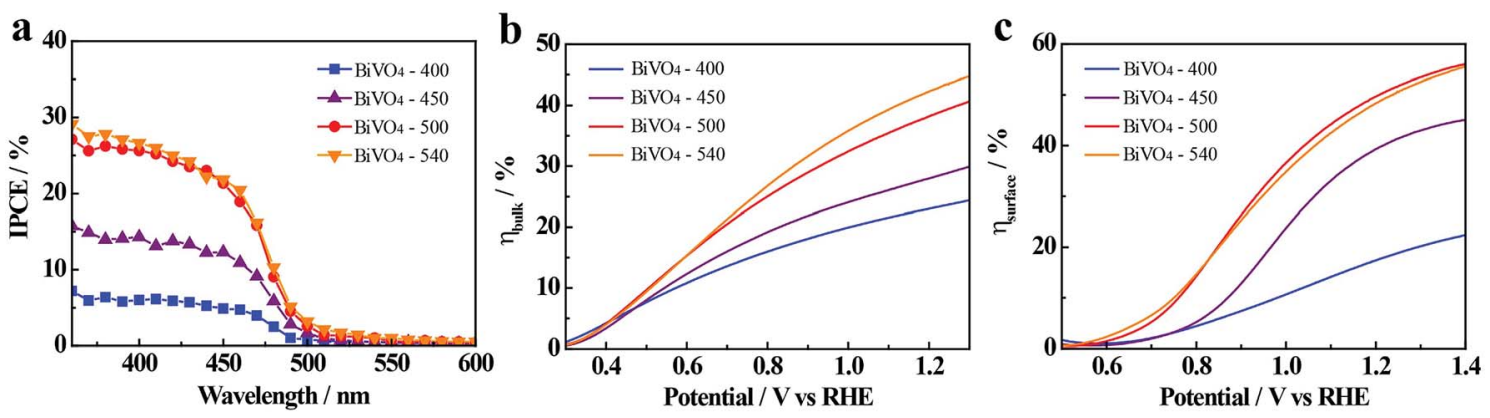

Fig. 4 (a) The incident photon to electron conversion efficiency spectra (IPCE) of $\mathrm{BiVO}_{4}-n$ samples, measured at $1.23 \mathrm{~V}$ vs. RHE in $0.1 \mathrm{M} \mathrm{KPi}$ buffer. Charge separation efficiency (b) in the bulk and (c) on the surface. 

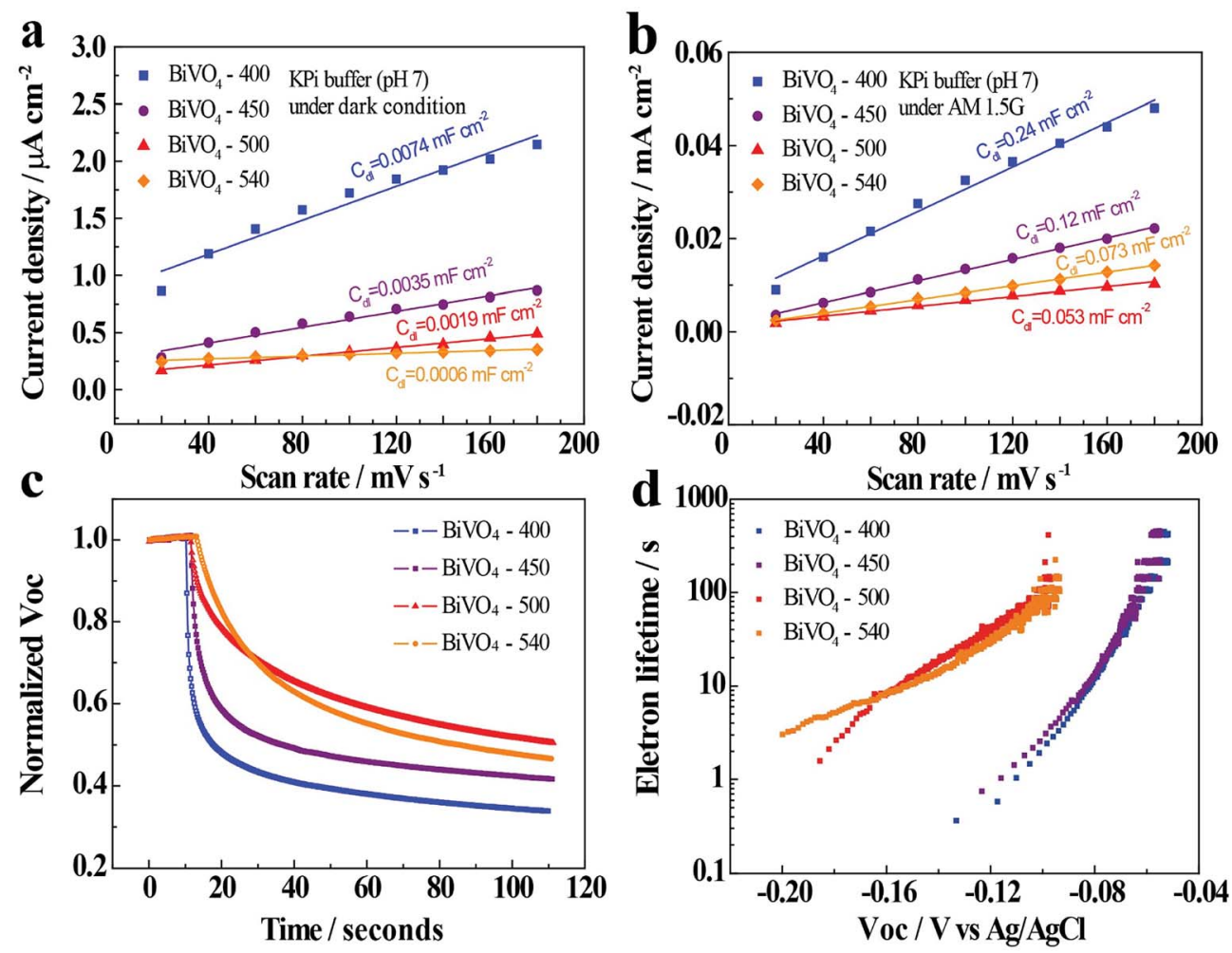

Fig. 5 Current density $\left(J=0.5 \times\left(J_{a}-J_{c}\right)\right)$ as a function of scan rates in (a) dark and (b) in AM 1.5G illuminated conditions. $J_{a}$ and $J_{c}$ present the anodic and cathodic current densities recorded at $0.54 \mathrm{~V}$ vs. RHE under dark and $0.3 \mathrm{~V}$ vs. RHE under illuminated conditions. (c) Normalized open-circuit photovoltage decay $\left(V_{\text {oc }}\right)$ curves of $\mathrm{BiVO}_{4}-n$ samples in $0.1 \mathrm{M} \mathrm{KPi} \mathrm{buffer}$. (d) The potential dependent photoelectron lifetime plots for $\mathrm{BiVO}_{4}-n$.

Meanwhile, when illuminated, the $C_{\mathrm{dl}}$ is determined to be $0.240,0.120,0.053,0.073 \mathrm{mF} \mathrm{cm}{ }^{-2}$ for $\mathrm{BiVO}_{4}-400, \mathrm{BiVO}_{4}-450$, $\mathrm{BiVO}_{4}-500$, and $\mathrm{BiVO}_{4}-540$, respectively (Fig. $5 \mathrm{~b}$ ). The $C_{\mathrm{dl}}$ values show a decreasing trend with the increase in the annealing temperature. These results are consistent with that of the dark condition. However, the increased current density in the illuminated condition exhibits an increase in the $C_{\mathrm{dl}}$ values. In other words, even though the $\mathrm{BiVO}_{4}$ samples prepared at lower temperatures produce higher electrochemically active surface areas, their photocurrents are lower than the $\mathrm{BiVO}_{4}$ samples prepared at higher temperature (Fig. 3).

In order to better assess the contrasting effects of annealing temperatures on EC in dark and PEC performance under light illumination, open-circuit photovoltage decay (OCPVD) is measured for all the $\mathrm{BiVO}_{4}-n$ samples (Fig. S14 $\dagger$ ). OCPVD consists of turning off the illumination at a steady state and monitoring the subsequent decay of open-circuit photovoltage $\left(V_{\text {oc }}\right)$ with time. In open-circuit condition under illumination, photo-excitation causes gradual accumulation of electrons in $\mathrm{BiVO}_{4}$ photoelectrode, which results in an upshift of the quasiFermi level and built-up of $V_{\text {oc }}{ }^{52,53}$ Since no current can flow to the external circuit, the electron accumulation is in competition against the dissipation processes, particularly, against charge recombination. ${ }^{54}$ When illumination is turned off, the charge recombination process solely dominates, leading to $V_{\mathrm{oc}}$ decay. It indicates that a longer $V_{\mathrm{oc}}$ decay time points to a smaller charge recombination rate of the sample. Furthermore, the normalized
$V_{\text {oc }}$ after the light is turned off for all the $\mathrm{BiVO}_{4}$ samples are presented in Fig. 5c. The OCPVD result shows that the $\mathrm{BiVO}_{4}$ thin film photoelectrode annealed at higher temperature has the longer $V_{\text {oc }}$ decay time, suggesting its less charge recombination. The $V_{\mathrm{oc}}$ decay rate is directly related to the photoelectron lifetime:

$$
\tau=\frac{k_{\mathrm{B}} T}{e}\left(\frac{\mathrm{d} V_{\mathrm{oc}}}{\mathrm{d} t}\right)^{-1}
$$

where, $\tau$ is the potential dependent photoelectron lifetime, $k_{\mathrm{B}}$ is Boltzmann constant, $T$ is the temperature, $e$ is elemental electron charge, and $V_{\text {oc }}$ is the open-circuit voltage at time $t$. The calculated potential dependent photoelectron lifetime is presented in Fig. 5d. It is observed that the photoelectron lifetime increases with decreasing $V_{\text {oc }}$. The $\mathrm{BiVO}_{4}$ samples prepared at higher temperature show relatively longer electron lifetime, leading to their better photocurrent performance.

\section{Conclusions}

The results of this work show that the crystallinity of the $\mathrm{BiVO}_{4}$ thin film electrodes is improved and average grain size is increased with the increase in the annealing temperature. A lower annealing temperature produces more electrochemically active sites, which is beneficial to EC performance under dark condition, while a higher annealing temperature leads to less electron-hole recombination and a better PEC performance 
under illumination. This work provides insights into the effects of annealing temperature in $\mathrm{BiVO}_{4}$ thin film photoelectrodes, highlights the importance of controlling annealing temperature of $\mathrm{BiVO}_{4}$ for the benefit of enhancing performance, and is thus significant to the future development of metal oxide semiconductor-based thin film photoelectrodes.

\section{Conflicts of interest}

There are no conflicts to declare.

\section{Acknowledgements}

This project is based upon work supported by the King Abdullah University Science and Technology (KAUST) CCF fund, awarded to Water Desalination and Reuse Center (WDRC). The authors are grateful to other members of the KAUST Environmental Nanotechnology group for their insightful discussions.

\section{References}

1 Y. Bai, I. Mora-Seró, F. De Angelis, J. Bisquert and P. Wang, Titanium Dioxide Nanomaterials for Photovoltaic Applications, Chem. Rev., 2014, 114(19), 10095-10130.

2 D. Kang, T. W. Kim, S. R. Kubota, A. C. Cardiel, H. G. Cha and K.-S. Choi, Electrochemical Synthesis of Photoelectrodes and Catalysts for Use in Solar Water Splitting, Chem. Rev., 2015, 115(23), 12839-12887.

3 N. S. Lewis, Toward Cost-Effective Solar Energy Use, Science, 2007, 315(5813), 798-801.

4 M. G. Walter, E. L. Warren, J. R. McKone, S. W. Boettcher, Q. Mi, E. A. Santori and N. S. Lewis, Solar Water Splitting Cells, Chem. Rev., 2010, 110(11), 6446-6473.

5 D. Das, J. Plazas-Tuttle, I. V. Sabaraya, S. S. Jain, T. SaboAttwood and N. B. Saleh, An elegant method for large scale synthesis of metal oxide-carbon nanotube nanohybrids for nano-environmental application and implication studies, Environ. Sci.: Nano, 2017, 4(1), 60-68.

6 Y. Park, K. J. McDonald and K.-S. Choi, Progress in bismuth vanadate photoanodes for use in solar water oxidation, Chem. Soc. Rev., 2013, 42(6), 2321-2337.

7 S. Tokunaga, H. Kato and A. Kudo, Selective Preparation of Monoclinic and Tetragonal $\mathrm{BiVO}_{4}$ with Scheelite Structure and Their Photocatalytic Properties, Chem. Mater., 2001, 13(12), 4624-4628.

8 Y. Liang, T. Tsubota, L. P. A. Mooij and R. van de Krol, Highly Improved Quantum Efficiencies for Thin Film $\mathrm{BiVO}_{4}$ Photoanodes, J. Phys. Chem. C, 2011, 115(35), 17594-17598.

9 F. F. Abdi and R. van de Krol, Nature and Light Dependence of Bulk Recombination in Co-Pi-Catalyzed $\mathrm{BiVO}_{4}$ Photoanodes, J. Phys. Chem. C, 2012, 116(17), 9398-9404.

10 X. Chang, T. Wang, P. Zhang, J. Zhang, A. Li and J. Gong, Enhanced Surface Reaction Kinetics and Charge Separation of $\mathrm{p}-\mathrm{n}$ Heterojunction $\mathrm{Co}_{3} \mathrm{O}_{4} / \mathrm{BiVO}_{4}$ Photoanodes, J. Am. Chem. Soc., 2015, 137(26), 8356-8359.

11 L. Zhou, C. Zhao, B. Giri, P. Allen, X. Xu, H. Joshi, Y. Fan, L. V. Titova and P. M. Rao, High Light Absorption and
Charge Separation Efficiency at Low Applied Voltage from Sb-Doped $\quad \mathrm{SnO}_{2} / \mathrm{BiVO}_{4} \quad$ Core/Shell Nanorod-Array Photoanodes, Nano Lett., 2016, 16(6), 3463-3474.

12 J. Su, L. Guo, N. Bao and C. A. Grimes, Nanostructured $\mathrm{WO}_{3} /$ $\mathrm{BiVO}_{4} \quad$ Heterojunction Films for Efficient Photoelectrochemical Water Splitting, Nano Lett., 2011, 11(5), 1928-1933.

13 B.-Y. Cheng, J.-S. Yang, H.-W. Cho and J.-J. Wu, Fabrication of an Efficient $\mathrm{BiVO}_{4}-\mathrm{TiO}_{2}$ Heterojunction Photoanode for Photoelectrochemical Water Oxidation, ACS Appl. Mater. Interfaces, 2016, 8(31), 20032-20039.

14 Y. Hu, D. Li, Y. Zheng, W. Chen, Y. He, Y. Shao, X. Fu and G. Xiao, $\mathrm{BiVO}_{4} / \mathrm{TiO}_{2}$ nanocrystalline heterostructure: a wide spectrum responsive photocatalyst towards the highly efficient decomposition of gaseous benzene, Appl. Catal., $B, 2011,104(1), 30-36$.

15 X. Zheng, B. Sciacca, E. C. Garnett and L. Zhang, AgFeS $2_{2}^{-}$ Nanowire-Modified $\mathrm{BiVO}_{4} \quad$ Photoanodes for Photoelectrochemical Water Splitting, ChemPlusChem, 2016, 81(10), 1075-1082.

16 H. S. Park, K. E. Kweon, H. Ye, E. Paek, G. S. Hwang and A. J. Bard, Factors in the Metal Doping of $\mathrm{BiVO}_{4}$ for Improved Photoelectrocatalytic Activity as Studied by Scanning Electrochemical Microscopy and First-Principles Density-Functional Calculation, J. Phys. Chem. C, 2011, 115(36), 17870-17879.

17 S. K. Cho, H. S. Park, H. C. Lee, K. M. Nam and A. J. Bard, Metal Doping of $\mathrm{BiVO}_{4}$ by Composite Electrodeposition with Improved Photoelectrochemical Water Oxidation, J. Phys. Chem. C, 2013, 117(44), 23048-23056.

18 K. P. S. Parmar, H. J. Kang, A. Bist, P. Dua, J. S. Jang and J. S. Lee, Photocatalytic and Photoelectrochemical Water Oxidation over Metal-Doped Monoclinic $\mathrm{BiVO}_{4}$ Photoanodes, ChemSusChem, 2012, 5(10), 1926-1934.

19 L. Zhang, E. Reisner and J. J. Baumberg, Al-doped ZnO inverse opal networks as efficient electron collectors in BiVO $_{4}$ photoanodes for solar water oxidation, Energy Environ. Sci., 2014, 7(4), 1402-1408.

20 L. Zhang, L. O. Herrmann and J. J. Baumberg, Size Dependent Plasmonic Effect on $\mathrm{BiVO}_{4}$ Photoanodes for Solar Water Splitting, Sci. Rep., 2015, 5, 16660.

21 L. Zhang, C.-Y. Lin, V. K. Valev, E. Reisner, U. Steiner and J. J. Baumberg, Plasmonic Enhancement in $\mathrm{BiVO}_{4}$ Photonic Crystals for Efficient Water Splitting, Small, 2014, 10(19), 3970-3978.

22 Y. Deng, L. Tang, C. Feng, G. Zeng, J. Wang, Y. Zhou, Y. Liu, B. Peng and H. Feng, Construction of plasmonic Ag modified phosphorous-doped ultrathin $\mathrm{g}-\mathrm{C}_{3} \mathrm{~N}_{4}$ nanosheets/BiVO photocatalyst with enhanced visible-near-infrared response ability for ciprofloxacin degradation, J. Hazard. Mater., 2018, 344, 758-769.

23 Z. Wei, D. Benlin, Z. Fengxia, T. Xinyue, X. Jiming, Z. Lili, L. Shiyin, D. Y. C. Leung and C. Sun, A novel 3D plasmonic p-n heterojunction photocatalyst: $\mathrm{Ag}$ nanoparticles on flower-like $\mathrm{p}-\mathrm{Ag}_{2} \mathrm{~S} / \mathrm{n}-\mathrm{BiVO}_{4}$ and its excellent photocatalytic reduction and oxidation activities, Appl. Catal., B, 2018, 229, 171-180. 
24 D. Wang, R. Li, J. Zhu, J. Shi, J. Han, X. Zong and C. Li, Photocatalytic Water Oxidation on $\mathrm{BiVO}_{4}$ with the Electrocatalyst as an Oxidation Cocatalyst: Essential Relations between Electrocatalyst and Photocatalyst, $J$. Phys. Chem. C, 2012, 116(8), 5082-5089.

25 L. Xia, J. Bai, J. Li, Q. Zeng, L. Li and B. Zhou, Highperformance $\mathrm{BiVO}_{4}$ photoanodes cocatalyzed with an ultrathin $\alpha-\mathrm{Fe}_{2} \mathrm{O}_{3}$ layer for photoelectrochemical application, Appl. Catal., B, 2017, 204(suppl. C), 127-133.

26 T. Palaniselvam, L. Shi, G. Mettela, D. H. Anjum, R. Li, K. P. Katuri, P. E. Saikaly and P. Wang, Vastly Enhanced $\mathrm{BiVO}_{4}$ Photocatalytic OER Performance by $\mathrm{NiCoO}_{2}$ as Cocatalyst, Adv. Mater. Interfaces, 2017, 4(19), 1700540.

27 M. Kan, D. Xue, A. Jia, X. Qian, D. Yue, J. Jia and Y. Zhao, A highly efficient nanoporous $\mathrm{BiVO}_{4}$ photoelectrode with enhanced interface charge transfer Co-catalyzed by molecular catalyst, Appl. Catal., B, 2018, 225, 504-511.

28 S. M. Thalluri, C. Martinez Suarez, M. Hussain, S. Hernandez, A. Virga, G. Saracco and N. Russo, Evaluation of the Parameters Affecting the Visible-LightInduced Photocatalytic Activity of Monoclinic $\mathrm{BiVO}_{4}$ for Water Oxidation, Ind. Eng. Chem. Res., 2013, 52(49), 1741417418.

29 A. Chemseddine, K. Ullrich, T. Mete, F. F. Abdi and R. van de Krol, Solution-processed multilayered $\mathrm{BiVO}_{4}$ photoanodes: influence of intermediate heat treatments on the photoactivity, J. Mater. Chem. A, 2016, 4(5), 1723-1728.

30 S. Hernández, G. Gerardi, K. Bejtka, A. Fina and N. Russo, Evaluation of the charge transfer kinetics of spin-coated $\mathrm{BiVO}_{4}$ thin films for sun-driven water photoelectrolysis, Appl. Catal., B, 2016, 190(suppl. C), 66-74.

31 S. N. F. M. Nasir, M. A. M. Teridi, M. Ebadi, J. S. Sagu, M. Y. Sulaiman, N. A. Ludin and M. A. Ibrahim, Annealing effect on the photoelectrochemical properties of $\mathrm{BiVO}_{4}$ thin film electrodes, Malaysian Journal of Analytical Sciences, 2015, 19(6), 1250-1255.

32 A. Khorsand Zak, W. H. Abd. Majid, M. E. Abrishami and R. Yousefi, X-ray analysis of ZnO nanoparticles by Williamson-Hall and size-strain plot methods, Solid State Sci., 2011, 13(1), 251-256.

33 P. Brack, J. S. Sagu, T. A. N. Peiris, A. McInnes, M. Senili, K. G. U. Wijayantha, F. Marken and E. Selli, AerosolAssisted CVD of Bismuth Vanadate Thin Films and Their Photoelectrochemical Properties, Chem. Vap. Deposition, 2015, 21(1-2-3), 41-45.

34 N. Butenko, A. I. Tomaz, O. Nouri, E. Escribano, V. Moreno, S. Gama, V. Ribeiro, J. P. Telo, J. C. Pesssoa and I. Cavaco, DNA cleavage activity of $\mathrm{VIVO}(\text { acac })_{2}$ and derivatives, $J$. Inorg. Biochem., 2009, 103(4), 622-632.

35 G. P. Nagabhushana, G. Nagaraju and G. T. Chandrappa, Synthesis of bismuth vanadate: its application in $\mathrm{H}_{2}$ evolution and sunlight-driven photodegradation, J. Mater. Chem. A, 2013, 1(2), 388-394.

36 J. H. Nobbs, Kubelka-Munk Theory and the Prediction of Reflectance, Rev. Prog. Color. Relat. Top., 1985, 15(1), 66-75.

37 A. Kudo, K. Omori and H. Kato, A Novel Aqueous Process for Preparation of Crystal Form-Controlled and Highly
Crystalline $\mathrm{BiVO}_{4}$ Powder from Layered Vanadates at Room Temperature and Its Photocatalytic and Photophysical Properties, J. Am. Chem. Soc., 1999, 121(49), 11459-11467.

38 Z. Zhao, Z. Li and Z. Zou, Electronic structure and optical properties of monoclinic clinobisvanite $\mathrm{BiVO}_{4}$, Phys. Chem. Chem. Phys., 2011, 13(10), 4746-4753.

39 D. Wang, H. Jiang, X. Zong, Q. Xu, Y. Ma, G. Li and C. Li, Crystal Facet Dependence of Water Oxidation on $\mathrm{BiVO}_{4}$ Sheets under Visible Light Irradiation, Chem.-Eur. J., 2011, 17(4), 1275-1282.

40 S. M. Thalluri, C. Martinez Suarez, S. Hernández, S. Bensaid, G. Saracco and N. Russo, Elucidation of important parameters of $\mathrm{BiVO}_{4}$ responsible for photo-catalytic $\mathrm{O}_{2}$ evolution and insights about the rate of the catalytic process, Chem. Eng. J., 2014, 245(suppl. C), 124-132.

41 S. Wang, P. Chen, J.-H. Yun, Y. Hu and L. Wang, An Electrochemically Treated $\mathrm{BiVO}_{4}$ Photoanode for Efficient Photoelectrochemical Water Splitting, Angew. Chem., 2017, 129(29), 8620-8624.

42 F. F. Abdi, L. Han, A. H. M. Smets, M. Zeman, B. Dam and R. van de Krol, Efficient solar water splitting by enhanced charge separation in a bismuth vanadate-silicon tandem photoelectrode, Nat. Commun., 2013, 4, 2195.

43 J. K. Cooper, S. Gul, F. M. Toma, L. Chen, Y.-S. Liu, J. Guo, J. W. Ager, J. Yano and I. D. Sharp, Indirect Bandgap and Optical Properties of Monoclinic Bismuth Vanadate, J. Phys. Chem. C, 2015, 119(6), 2969-2974.

44 Z. Zhang, X. Yang, M. N. Hedhili, E. Ahmed, L. Shi and P. Wang, Microwave-Assisted Self-Doping of $\mathrm{TiO}_{2}$ Photonic Crystals for Efficient Photoelectrochemical Water Splitting, ACS Appl. Mater. Interfaces, 2014, 6(1), 691-696.

45 X. Ren, Z. Yang, D. Yang, X. Zhang, D. Cui, Y. Liu, Q. Wei, H. Fan and S. Liu, Modulating crystal grain size and optoelectronic properties of perovskite films for solar cells by reaction temperature, Nanoscale, 2016, 8(6), 3816-3822.

46 H. Gong, N. Freudenberg, M. Nie, R. v. d. Krol and K. Ellmer, $\mathrm{BiVO}_{4}$ photoanodes for water splitting with high injection efficiency, deposited by reactive magnetron co-sputtering, AIP Adv., 2016, 6(4), 045108.

47 D. K. Zhong, S. Choi and D. R. Gamelin, Near-Complete Suppression of Surface Recombination in Solar Photoelectrolysis by "Co-Pi" Catalyst-Modified W:BiVO 4 , J. Am. Chem. Soc., 2011, 133(45), 18370-18377.

48 S. K. Choi, W. Choi and H. Park, Solar water oxidation using nickel-borate coupled $\mathrm{BiVO}_{4}$ photoelectrodes, Phys. Chem. Chem. Phys., 2013, 15(17), 6499-6507.

49 F. Le Formal, K. Sivula and M. Grätzel, The Transient Photocurrent and Photovoltage Behavior of a Hematite Photoanode under Working Conditions and the Influence of Surface Treatments, J. Phys. Chem. C, 2012, 116(51), 26707-26720.

50 L. M. Peter, Energetics and kinetics of light-driven oxygen evolution at semiconductor electrodes: the example of hematite, J. Solid State Electrochem., 2013, 17(2), 315-326.

51 Z. Zhang, L. Zhang, M. N. Hedhili, H. Zhang and P. Wang, Plasmonic Gold Nanocrystals Coupled with Photonic Crystal Seamlessly on $\mathrm{TiO}_{2}$ Nanotube Photoelectrodes for 
Efficient Visible Light Photoelectrochemical Water Splitting, Nano Lett., 2013, 13(1), 14-20.

52 R. P. Antony, P. S. Bassi, F. F. Abdi, S. Y. Chiam, Y. Ren, J. Barber, J. S. C. Loo and L. H. Wong, Electrospun Mo$\mathrm{BiVO}_{4}$ for Efficient Photoelectrochemical Water Oxidation: Direct Evidence of Improved Hole Diffusion Length and Charge separation, Electrochim. Acta, 2016, 211(suppl. C), 173-182.
53 Z. Zhang and P. Wang, Optimization of photoelectrochemical water splitting performance on hierarchical $\mathrm{TiO}_{2}$ nanotube arrays, Energy Environ. Sci., 2012, 5(4), 6506-6512.

54 N. Baram and Y. Ein-Eli, Electrochemical Impedance Spectroscopy of Porous $\mathrm{TiO}_{2}$ for Photocatalytic Applications, J. Phys. Chem. C, 2010, 114(21), 9781-9790. 